\title{
PREDICTION OF CAVITATION EROSION RATE
}

\author{
M. A. Hosien and S. M. Selim \\ Mechanical Power Engineering Department, Faculty of Engineering, \\ Minoufiya University, Shebin El-Kom, Egypt
}

\begin{abstract}
In the present paper a power- law relationship between erosion rate and cumulative erosion for cavitation has been presented. In order to verify this relationship, erosion tests were conducted in a closed circuit water tunnel in which pure aluminum test specimens were mounted in the wake of cavitating source. Erosion was determined by weight loss on the side wall specimens. The erosion tests were conducted for four sizes of $60^{\circ}$ symmetric wedges at wide range of flow velocities and cavitation numbers. The present experimental data confirm the proposed power-law relationship. Moreover, data from various previous investigations of cavitation and liquid impingement devices confirm this relation. The present analysis supports the view that the predominate erosion mechanism appear to be the same in all types of erosion. From the proposed relationship it is possible to predict the magnitude of erosion in a field system with the data from a laboratory device or to predict how much material will be lost in a number of years or how long it will take to lose a certain amount of material for adequate, performance of the component.

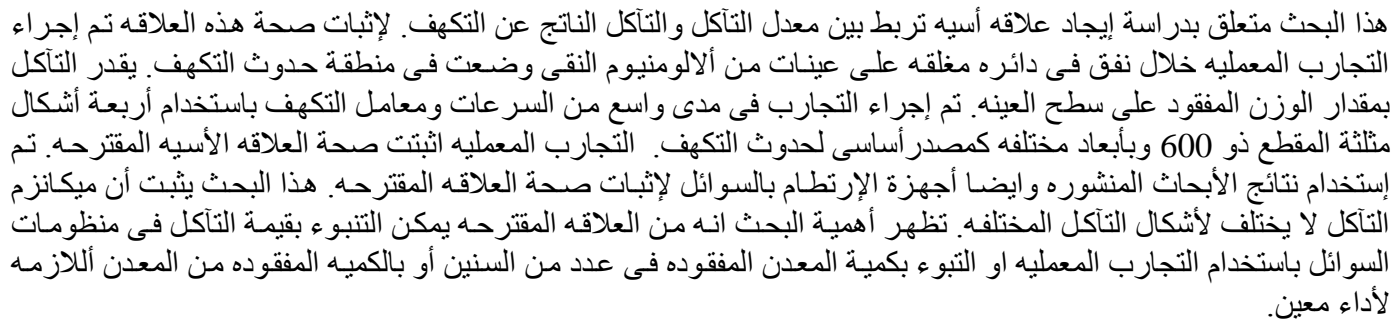

Keywords: Cavitation, erosion.

\section{INTRODUCTION}

Cavitation and its related effects are still playing a major role in the design and use of fluid machinery. Cavitation erosion is a form of damage which occurs in many types of fluid machinery such as water turbines, pumps and torque converters, as well as in industrial machines such as cylinder liners of diesel engines, ship propellers, valves and bearing. The problem of describing by mathematical relations the cavitation erosion characteristic curves was studied by $[1,2]$. The objective is to obtain a function representing a curve that gives an acceptable approximation of the experimental points both for cumulative losses and erosion velocities. Hattori and Ishikura [3, 4] have constructed a database on cavitation erosion tests that were carried out from 1970 to 2002 and they concluded that the erosion resistance of carbon steel increases proportionally with 2.4th power of the Vickers hardness with a correlation coefficient of 0.92 . Cavitation erosion data obtained from 2003 to 2005 was added to the existing database [4].
Hattori and Kitagawa [5] constructed a database of cavitation erosion and analyzed carbon steel data. In their study, erosion resistance was analyzed for cast iron, aluminum alloys, copper alloys, and titanium alloys, in comparison with regular carbon steels. The cavitation erosion resistance can be separately evaluated in terms of hardness for these alloys.

Szkodo [6] presented mathematical model describing cavitation erosion of materials. The model of cavitation erosion is based on Weibull,s distribution. The model describes the influence of material properties i.e. relative resistance to plastic deformation and stress intensity factor of hardened surface layer under cavitation loading on the cavitation erosion of materials. Tôn-Thât [7] studied the cavitation erosion rates for several years, in particular in hydraulic turbine runner, to try to understand the different degradation mechanisms related to this phenomenon. The maximum depth of erosion, the mean depth of erosion, and the mean depth of erosion rate are determined. Dunarea [8] presented the definitions regarding the industrial tribosystems and cavitation tribomodels. Also, presented data from the reference literature regarding 
the parameter influence of the superficial layer in the cavitation destruction: surfaces roughness, mechanical characteristics, indirect stress and deformations.

Bordeasu et al. [9] presented an analytical model to obtain the cavitation erosion characteristic curves $\mathrm{m}(\mathrm{t})$ and $\mathrm{v}(\mathrm{t})$. The model allows obtaining simultaneously both curves, with good precision, taken into account the multitude of factors influencing the material erosion. Their model was applied on three types of steel. Thiruvengadam et al. [10] disclosed a process and apparatus for high speed material removal with relatively low specific energy input requirements.

Since the first consideration of erosion problem in hydraulic machinery, the prediction of erosion rates have greatly interested constructors in general. The erosion rate of hydraulic machinery determines the duration of guarantees and sets certain limitations for designs. There have been many attempts in the past to predict cavitation erosion rates of different materials tested various equipment, some investigators have used the average erosion rate versus cumulative erosion relationship for comparison [11]. However, the different features of the curves resulting from comparison have not been fully investigated. In general, none of these methods yield satisfactory results over a relatively large domain of applications. Therefore, the present work is intended to develop a power law relation between erosion rate and cumulative erosion in both the acceleration and deceleration zones of the erosion process.

\section{EXPERIMENTAL PROGRAMME}

\subsection{Apparatus}

The rig used for the present erosion experiments was a two dimensional closed circuit water tunnel at Faculty of engineering, Minoufiya University. The working section of 42.5 x $18.5 \mathrm{~mm}$ cross-section was made from $20 \mathrm{~mm}$ thick steel to resist the stresses resulting from bubble collapse. Two Perspex windows of thickness $5.08 \mathrm{~cm}$ were machined to engage into windows of the two smaller sides of the working section, and were backed up by at two steel windows. This is to observe the cavity during the operation of the tunnel for long period and to keep the operation condition constant. The circuit could be pressurized in order that the pressure and flow velocity could be varied independently. Figure 1 show the cavitation research water tunnel and its major components. Details of the water tunnel were mentioned in ref. [12]. Figure 2 show details of $60^{\circ}$ symmetrical wedge and its position in the test section.
The cavitation number at the vena contracta can be deduced from the measured value of the upstream cavitation number ( $\sigma_{o}$ ) as follows:

$$
\sigma=\frac{\sigma_{o}-\sigma_{o b}}{1+\sigma_{o b}}
$$

where

$$
\sigma_{o}=\frac{p_{o}-p_{v}}{\frac{1}{2} \rho u_{o}^{2}}
$$

Where $p_{o}$ and $u_{o}$ are respectively, the static pressure and fluid velocity at the upstream of cavitation inducer, $p_{v}$ is the vapor pressure at the bulk liquid temperature and $\rho$ the fluid density. $\sigma_{o b}$ is the value of $\sigma_{o}$ when breakdown condition has been reached. The calculation of $\sigma$ is dependent on the accuracy of measuring the pressure, temperature and velocity. The velocity at the vena contracta can be obtained from the following equation: $\boldsymbol{u}=\boldsymbol{u}_{o} \sqrt{\sigma_{o b}+1} \mathrm{~m} / \mathrm{s}$.

\subsection{Test Conditions}

The experimental work was carried out using commercially pure aluminum specimens flush mounted in the cover of the working section downstream of cavitation source. The specimen shape used was $160 \mathrm{~mm}$ length with $42.5 \times 6 \mathrm{~mm}$ cross-section. The velocity was varied from $26.9 \mathrm{~m} / \mathrm{s}$ to $42.5 \mathrm{~m} / \mathrm{s}$ at a constant cavitation number of 0.113 . The cavitation number was varied from 0.066 to 0.128 at a constant flow velocity of $37.89 \mathrm{~m} / \mathrm{s}$. The tunnel water temperature of $32 \pm 2$ oc was kept fairly constant by regulating the amount of cooling coils which were fitted inside the tunnel downstream tank.

Equilateral prisms $60^{\circ}$ wedge was adopted as the basic forms for the source of cavitation. Four equilateral prisms of 15, 17, 22 and $24 \mathrm{~mm}$ sidewall length with $18.5 \mathrm{~mm}$ height were used.

\subsection{Measurements and Error}

A precision electronic balance, Oertling LA 264, whose lowest count was $0.1 \mathrm{mg}$ was used to measure the weight loss of the specimen. For weight loss-time studies the specimen was repeatedly subjected to cavitation attack for define intervals of time until satisfactory points in the steady-state weight loss zone have been obtained.

A pressure transducer of model Phillips order number. 9880/20 was used to measure the inlet pressure of the test section. This pressure is used to calculate the cavitation number. The accuracy of the pressure measurement was about $\pm 0.4 \%$. 
The velocity of the flow in the working section was obtained from the output signal of an electromagnetic flow meter. The accuracy of velocity was about $0.5 \%$. This means that the uncertainty of vapor pressure is insignificant. Therefore, the extreme error in cavitation number is $1.65 \%$. The accuracy of weight loss, particularly in the steady-state weight loss zone was within $\pm 0.5 \%$. Considering the error in the operation conditions, it appears that the weight loss results are accurate to within $\pm 2.5 \%$.

\subsection{Experimental Results}

A wide range of velocities and cavitation numbers were tested to demonstrate the weight-loss rate. Figure 3 shows photographs of the erosion patterns produced by $22 \mathrm{~mm}$ equilateral triangular $\left(60^{\circ}\right.$ symmetric wedge $)$ for sidewall aluminum specimens at a constant flow velocity of $37.39 \mathrm{~m} / \mathrm{s}$, with different cavitation numbers. The portions of the cumulative weight-loss curves considered to be of constant slope were taken to be the weight loss rate (WLR) for respective test velocities, cavitation numbers and source size. Figures 4 and 5 show typical weight loss curves with different exposure time. In order to obtain the erosion rate at a given flow condition, mass loss was measured as a function of exposure time. Some of these results are presented graphically in figures 4 and 5 . These figures show clearly the effect of flow conditions and cavitating source size on the weight loss. From these data, it is possible to generate an erosion rate curves figures 6 and 7. Figures 6 and 7 show the variation of weight loss rate (WLR) with exposure time for 17 and 22 $\mathrm{mm} 60^{\circ}$ symmetrical wedges cavitating sources. These figures are representative of curves found in all the present erosion tests at constant velocity and cavitation number, respectively. These figures show that the process of cavitation erosion can be divided into three stages: (I) an incubation period, (II) an acceleration period, (III) a fairly steady-state. These three stages agree with the typical curves of erosion rate versus exposure time reported in literature by many investigators.

Figures 6 and 7 are typical curves of the variation of WLR versus WL curves for 17 and $22 \mathrm{~mm} 60^{\circ}$ symmetrical wedges at constant flow velocity and constant cavitation number, respectively. The use of WLR versus cumulative WL gives a satisfactory analysis of the data and is very important in understanding the phenomenon of erosion as well as in assessing erosion damage in an actual machine from laboratory data. In order to establish this relationship, for the measurements described here, the weight loss rates plotted on a double logarithmic scale as a function of cumulative weight loss in figures 8 to 11 for the four cavitating sources at different velocities and cavitating numbers. If a power law holds the data should plot as a straight line with the slope being the exponent of cumulative weight loss. In figures 8 to 11 , the variation of weight loss rate (ER) with cumulative weight loss rate (E) could be expressed as a power law, ER $\alpha$ En in acceleration zone of the curve and ER $\alpha$ E-m in deceleration zone of the curve. The values of $n$ and $m$ varied between 0.56 and 0.7 and 0.59 and 0.71 , respectively. The values of $\mathrm{n}$ and $\mathrm{m}$ are presented in table (1) for all tests conducted here.

\section{EXPERIMENTAL DATA REPORTED IN PREVIOUS LITERATURE}

In order to asses and to confirm the universal nature of the proposed relationship extensive cavitation erosion data reported by other investigators using different equipment were used for the present analysis. Cavitation erosion data [8,9] using vibratory device, rotating disk device [11], venturi device [4, 5, 7 and 13], magnetostriction oscillators [14] and liquid impingement device [15] have been used in the analysis.

\section{RELATIONSHIP BETWEEN EROSION RATE AMD CUMULATIVE EROSION}

Several forms of the erosion rate versus time curves have been reported in the literature depending on the properties of materials, testing facilities and experimental conditions. Fig. 12 reported by [11] indicates a typical set of erosion rate versus cumulative erosion curves on different materials tested in rotating disk device. This figure suggests similar patterns for all materials used in their investigation. In addition, the curves in Fig. 12 could be divided into two zones: (i) acceleration zone, during which, the erosion rate increases with the cumulative erosion, and (ii) deceleration zone, during which, the erosion rate decreases with the cumulative erosion. Based on these findings the present analysis has been made.

Figures 12 to 23 present typical sets of plots of erosion rate versus cumulative erosion using vibratory device [8,9], rotating disk device [11], water tunnel device [4, 5, 7 and 13], magnetostriction [14] and liquid impingement device [15]. Most of the data presented in figures $12,16,17,19,20$, and 22 represent the acceleration and deceleration zones. However, figures 13, 14, 15, 18, 21, and 23 represent the acceleration zone since the experiments were not conducted for long exposures. Thus most of the data on deceleration zone were not available. In this analysis, increasing and decreasing erosion rates as a function of cumulative erosion in the log-log curves are termed as acceleration and deceleration zones. This is similar to acceleration (an increase of erosion rate with time) and deceleration (a decrease, of erosion rate with time) periods in the erosion rate versus time curves. 
The experimental points of all curves may individually be represented by separate power-law relationships during the acceleration and deceleration zones. The equation for the acceleration zone is written as:

$$
E R=C_{1} \cdot E^{n}
$$

The rate of cumulative erosion is given by:

$$
E R=E / t \text { or } \frac{d E}{d t}
$$

From equations (1) and (2) the following expression for the cumulative volume loss is obtained,

$$
E=\left(\mathrm{C}_{1} t\right)^{1 /(1-n)}
$$

Differentiation of equation (3) with respect to $t$ results in

$$
\frac{d E}{d t}=\left(\mathrm{C}_{1} t^{n}\right)^{1 /(1-n)} /(1-\mathrm{n})
$$

or

$$
\frac{d E}{d t}=\mathrm{k}_{1} \cdot t^{n_{1}}
$$

where

$$
k_{1}=C_{1}{ }^{1 /(1-n)} /(1-n) \text { and } n_{1}=n /(1-n) .
$$

Similarly, the equation for the deceleration zone (following the peak) is represented as,

$$
\begin{gathered}
E / t=C_{2} \cdot E^{-m} . \\
E=\left(C_{2} . t\right)^{1 /(1+m)}
\end{gathered}
$$

or

Where: $\mathrm{C} 2$ and $\mathrm{m}$ are empirical constants to be determined from data analysis.

Differentiation of equation (7) with respect to $t$ results in:

$$
\begin{gathered}
\frac{d E}{d t}=E /(1+m) t \\
\frac{d E}{d t}=k_{2} t^{n_{2}}
\end{gathered}
$$

Where

$$
k_{2}=C_{2}{ }^{1 /(1+m)} \text { and } n_{2}=-m /(1+m)
$$

The exponents and correlation coefficients obtained by least-squares fit of the experimental data points in figures 1 to 8 are presented in table 1 . The intersection points of the acceleration line with deceleration line in figures $1,3,4$ and 5 may be obtained by equating equations (1) and (6), i.e.

$$
\begin{aligned}
& C_{1} E^{n}=C_{2} E^{-m} \\
& E_{m}=\left(C_{2} / C_{1}\right)^{1 /(n+m)}
\end{aligned}
$$

The value of $E$ in equation (11) corresponds to the maximum in the erosion rate versus cumulative erosion curve and the maximum value of erosion rate and time corresponding to this peak may be obtained by using either equation (3) or (7).

The following observations can be made from the results presented in table 1 . (a) exponents $n$ and $m$ appear to be almost equal except for brass I of rotating disk data, (b) a power-law relation also exists between erosion rate and exposure time equations (5) and (8), and (c) with a few numbers of the experimental data points the curves can be fitted. The advantage of this characteristic relation is that the maximum value of $\mathrm{dE} / \mathrm{dt}$ and time corresponding to this maximum may be estimated and a curve to represent deceleration zone can be approximately drawn from the intersection point.

\section{DISCUSSION}

To confirm the results of the present investigation, typical set of data using various devices [4-15] were analyzed and the results obtained are presented in figures.12 - 23. The correlation coefficients and exponents for the power-law correlation are presented in table 1 . Table 1 shows that the exponents $\mathrm{n}$ vary widely for different materials and experimental conditions.

It is clear from figures $12-23$ that each material is presented by a power-law relation during the acceleration zone and the experimental points agree well with the least-square-fit lines drawn. This supports the common nature of erosion phenomena, not only with various cavitation erosion devices, but also between cavitation and liquid impingement erosion processes. In addition, the universal relations support the view that the predominant operative phenomena appears to be the same in .all types of erosion. The analysis also supports the view that the total erosion always acts as a history of the surface in arriving at a particular average erosion rate.

Most of the data presented in figures, $(12-23)$ represent the acceleration zone since the experiments were not conducted for long exposures. Thus most of the data on deceleration zones were not available. However, it is possible to obtain curves for the deceleration zones from $\mathrm{Em}$ and the slopes $\mathrm{n}$ assuming $\mathrm{n} \approx \mathrm{m}$ (equations 1 and 6 ). 
From the foregoing it is possible to predict erosion rates in field machines from laboratory tests. In addition, the present characteristic relation is the more valuable approach for the design engineer who wishes to predict how much material will be lost in $\mathrm{X}$ years or how long it will take to reach a material loss E considered unacceptable for adequate performance of the component.

\section{CONCLUSIONS}

The conclusions which can be drawn from the foregoing analysis are:

1. A power law relationship between erosion rate and cumulative erosion during the acceleration and deceleration zones of erosion was observed. The exponents of the power-law relationships during these two zones are found to be almost equal.

2. The interesting features of these relationships are that fewer experimental points are required to establish erosion rates. In the light of these relationships, it is possible to assess the erosion likely in Field machines from laboratory tests or to predict the life of a machine operating under cavitation conditions.

3. Analysis of erosion data from various cavitation and liquid impingement devices conformed to this power-law relationship. This provides a basis for similarity of erosion in different cavitation devices and between cavitation and liquid impact erosion processes.

\section{REFERENCES}

[1] Steller, J., "International Cavitation Erosion Test-test Facilities and Experimental Results", 2-emes Journees cavitation, Paris March, p.1, 1992.

[2] Popviciu M., Bordeasu I.,"A Quantitative Method of Estimating the Cavitation Behaviour of Materials Tested in a Magnetostrictive Facility", Buletin Stiintific , Universitatea Politehnica "Timisoara", Vol 41 (55), 1996.

[3] Hattori, S. and Ishikura, R.," Construction of Database on Cavitation Erosion and Analyses of Carbon Steel Data", Wear 257 , 2004, 10221029.

[4] Hattori, S. and Ishikura, R.,"Revision of Cavitation Erosion Database and Analysis of Stainless Steel Data", Wear 268, 2010, 109_ 116.

[5] Hattori, S. and Kitagawa, T., "Analysis of Cavitation Erosion Resistance of Cast Iron and Nonferrous Metals Based on Database and Comparison with Carbon Steel Data", Wear 269, 2010, 443-448.

[6] Szkodo M., "Mathematical Description and Evaluation of Erosion Resistance of Materials" 13th International Scientific Conference on
Achievements in Mechanical and materials Engineering, May 2005.

[7] Tôn-Thât, L., "Experimental Comparison of Cavitation Erosion Rates of Different Steels used in Hydraulic Turbines", 25th IAHR Symposium on Hydraulic Machinery and Systems, Earth and Environmental Science 12, 2010, 012052.

[8] Dunarea de Jos, "The Parameter Influence on the Superficial Layer in Cavitation Destruction" V111, 2002 ,ISSN 1221-4590, Tribology.

[9] Bordeasu L., Patrascoiu C-tin, Popoviciu M. O. and Balasoiu V."An Analytical Model for the Cavitation Erosion Characteristic Curves", The 6th International Conference on Hydraulic Machinery and Hydrodynamics, Timisoara, Romania, October 21-22, 2004.

[10] Thiruvengadam, "Controlled Cavitation Erosion Process and System", U. S. Patent, Mar. 18, 1980.

[11] Veerabhadra Rao, P. and Syamala Rao, B.C., "Cavitation Erosion in Fluid Systems", ASME, 1981.

[12] Hosien, M. A. and Selim, S. M. "A Study on Tip Clearance Vortex Cavitation Inception", Engineering Research Journal, Faculty of Engineering, Mataria-Cairo, Helwan University, Vol.122, (June 2009), M1-M25.

[13] Symala Rao, B.C., and Chandrasekhara, D.V., "Cavity and Damage Characteristics for Cavitation in a Venturi", Water Power, 1974, 27-31.

[14] Young, S.G. and Johnsion, J. R., "Erosion by Cavitation or Impingement", ASTM STP, 408, p. $186,1967$.

[15] Hammitt, F.G., Chao, C., Kling, C. L., Mitchell, T. M., and Rogers, D. O.,"ASTM Round Rob in Test with Vibratory Cavitation and Liquid Impact Facilities of 6061-T6511 Aluminium Alloy, 316 Stainless Steel and Commercially Pure Nickel", Materials. Research and standards, Vol. 10, No. 10, pp. 16-23, 1970.

\section{NOMENCLATURE}

\begin{tabular}{|c|c|}
\hline A516 & low carbon steel \\
\hline b & $\begin{array}{l}\text { distance between the specimen } \\
\text { and the vibratory horn in } \mathrm{cm}\end{array}$ \\
\hline $\mathrm{Cu}-\mathrm{AL}$ & copper alloy \\
\hline C1 & constant \\
\hline $\mathrm{C} 2$ & empirical constants \\
\hline $\mathrm{HV}$ & Vickers hardness \\
\hline $\mathrm{m}(\mathrm{t})$ & eroded mass ( $\mathrm{g} / \mathrm{min})$ \\
\hline MDER & $\begin{array}{l}\text { mean depth of erosion rate } \\
(\mu \mathrm{m} / \mathrm{hr}, \mathrm{mm} 3 / \mathrm{hr}, \mathrm{mg} / \mathrm{hr})\end{array}$ \\
\hline $\mathrm{n}, \mathrm{m}$ & $\begin{array}{l}\text { empirical determined exponent } \\
\text { correlation coefficient }\end{array}$ \\
\hline
\end{tabular}


S15C

SUS304

SUSxxx

SCSxxx

$\mathrm{t}$

$\mathrm{u}$

$\mathrm{V}(\mathrm{t})$

$\mathrm{W}$

$\sigma$
$0.15 \%$ carbon steel

austenitic stainless steel

(18\% Cr-8\% Ni)

special use stainless steel typexxx

stainless casting steel typexxx

exposure time corresponding to

the cumulative erosion

flow velocity $(\mathrm{m} / \mathrm{s})$

erosion velocity ( $\mathrm{g} / \mathrm{min}$ )

wedge side length

cavitation number

\section{ABBREVIATION}

WL weight loss (mg)

WLR weight loss rate $(\mathrm{mg} / \mathrm{hr})$

Table 1, Exponents and Correlation coefficient for different materials tested in various devices

\begin{tabular}{|c|c|c|c|c|c|c|c|c|}
\hline \multirow{3}{*}{$\begin{array}{l}\text { Data source } \\
\text { and device }\end{array}$} & \multirow{3}{*}{ Material } & \multicolumn{3}{|c|}{ Test condition } & \multirow{2}{*}{\multicolumn{2}{|c|}{$\begin{array}{l}\text { Acceleration zone } \\
E R \propto E^{n} \\
\end{array}$}} & \multirow{2}{*}{\multicolumn{2}{|c|}{\begin{tabular}{|l} 
Deceleration zone \\
$E R \propto E^{-m}$ \\
\end{tabular}}} \\
\hline & & \multirow{2}{*}{\begin{tabular}{|l|} 
Inducer \\
size \\
$\mathrm{D}, \mathrm{mm}$ \\
\end{tabular}} & \multirow[t]{2}{*}{$U, m / s$} & \multirow{2}{*}{$\sigma$} & & & & \\
\hline & & & & & $\mathrm{n}$ & $\mathrm{r}$ & $\mathrm{m}$ & $\mathrm{r}$ \\
\hline \multirow{8}{*}{$\begin{array}{l}\text { Present } \\
\text { experiments: } \\
\text { Venture test } \\
\text { section; } \\
60^{\circ} \text { symmetric } \\
\text { wedge inducer, } \\
\text { Test liquid: tap } \\
\text { water. }\end{array}$} & \multirow[t]{8}{*}{$\begin{array}{l}\text { Pure } \\
\text { Aluminum }\end{array}$} & \multirow[t]{2}{*}{15} & \begin{tabular}{|l|}
$42, .5$ \\
37.9 \\
35.65 \\
30 \\
28
\end{tabular} & 0.113 & $\begin{array}{l}0.61 \\
0 . .59 \\
0.62 \\
0 . .58 \\
0 . .63\end{array}$ & $\begin{array}{l}0.998 \\
\text { 0. } 999 \\
\text { 0. } 998 \\
\text { 0. } 997 \\
\text { 0. } 994\end{array}$ & $\begin{array}{l}0.62 \\
0.63\end{array}$ & $\begin{array}{l}0.999 \\
0.997\end{array}$ \\
\hline & & & 37.89 & \begin{tabular}{|l|}
0.169 \\
0.096 \\
0.066
\end{tabular} & $\begin{array}{l}0.60 \\
0.63 \\
0.58\end{array}$ & $\begin{array}{l}0.997 \\
0.999 \\
0.996\end{array}$ & & \\
\hline & & \multirow[t]{2}{*}{17} & \begin{tabular}{|l|}
41.86 \\
37.89 \\
33.9 \\
29.91 \\
26.92 \\
\end{tabular} & 0.113 & $\begin{array}{l}0.65 \\
0.62 \\
0.63 \\
0.66 \\
0.64 \\
\end{array}$ & \begin{tabular}{|l|}
0.989 \\
0.991 \\
0.998 \\
0.996 \\
0.994 \\
\end{tabular} & & \\
\hline & & & 37.89 & \begin{tabular}{|l|}
0.152 \\
0.089 \\
0.065 \\
\end{tabular} & \begin{tabular}{|l|}
0.60 \\
0.63 \\
0.66 \\
\end{tabular} & \begin{tabular}{|l|}
0.999 \\
0.979 \\
0.994 \\
\end{tabular} & & \\
\hline & & \multirow[t]{2}{*}{22} & \begin{tabular}{|l|}
41.86 \\
37.89 \\
33.9 \\
29.91 \\
26.92 \\
\end{tabular} & 0.113 & \begin{tabular}{|l|}
0.62 \\
0.60 \\
0.63 \\
0.59 \\
0.62 \\
\end{tabular} & \begin{tabular}{|l|}
0.997 \\
0.998 \\
0.991 \\
0.999 \\
0,990 \\
\end{tabular} & $\begin{array}{l}0.65 \\
0.59\end{array}$ & \begin{tabular}{|l|}
0.988 \\
0.991
\end{tabular} \\
\hline & & & 37.39 & \begin{tabular}{|l|}
0.143 \\
0.089 \\
0.057 \\
\end{tabular} & \begin{tabular}{|l|}
0.63 \\
0.62 \\
0.61 \\
\end{tabular} & \begin{tabular}{|l|}
0.988 \\
0.985 \\
0.999 \\
\end{tabular} & & \\
\hline & & \multirow[t]{2}{*}{24} & \begin{tabular}{|l|}
42.5 \\
40.16 \\
37.89 \\
35.65 \\
30 \\
\end{tabular} & 0.113 & $\begin{array}{l}0.66 \\
0.67 \\
0.65 \\
0.7 \\
0.63\end{array}$ & \begin{tabular}{|l|}
0.996 \\
0.978 \\
0.994 \\
0.993 \\
0.984
\end{tabular} & 0.71 & 0.968 \\
\hline & & & 37.89 & \begin{tabular}{l|}
0.127 \\
0.091 \\
0.0635
\end{tabular} & $\begin{array}{l}0.65 \\
0.68 \\
0.59\end{array}$ & \begin{tabular}{|l|}
0.993 \\
0.999 \\
0.981
\end{tabular} & & \\
\hline
\end{tabular}


Table (1): Cont

\begin{tabular}{|c|c|c|c|c|c|}
\hline \multirow{3}{*}{ Data source and device } & \multirow{3}{*}{ Material } & \multicolumn{2}{|c|}{ Acceleration zone } & \multicolumn{2}{|c|}{ Deceleration zone } \\
\hline & & \multicolumn{2}{|c|}{$E R \propto E^{n}$} & \multicolumn{2}{|c|}{$E R \propto E^{-m}$} \\
\hline & & $\mathrm{n}$ & $\mathrm{r}$ & $\mathrm{m}$ & $\mathrm{r}$ \\
\hline $\begin{array}{l}\text { [4] Stationary specimen method. } \\
\text { Standoff distance: } 1 \mathrm{~mm} \text {. }\end{array}$ & $\begin{array}{l}\text { SUS316 }(\mathrm{HV}=180) \\
\text { SCS13 }(\mathrm{HV}=155) \\
\text { SUS304 }(\mathrm{HV}=185) \\
\text { SUS405 }(\mathrm{HV}=160) \\
\text { S15C }(\mathrm{HV}=144)\end{array}$ & $\begin{array}{l}0.628 \\
0.686 \\
0.705 \\
0.656 \\
0.574\end{array}$ & $\begin{array}{l}0.932 \\
0.915 \\
0.905 \\
0.84 \\
0.92\end{array}$ & $\begin{array}{l}0.0385 \\
---- \\
0.0390 \\
6.5 \\
6.8\end{array}$ & $\begin{array}{l}0.895 \\
----- \\
0.881 \\
0.835 \\
0.86\end{array}$ \\
\hline $\begin{array}{l}\text { [5] Stationary specimen method. } \\
\text { Standoff distance: } 1 \mathrm{~mm} \text {. }\end{array}$ & $\mathrm{S} 15 \mathrm{C}(99-37)$ & 0.631 & 0.835 & ---- & ----- \\
\hline $\begin{array}{l}\text { [7] Cavitation liquid jet erosion tests - } \\
\text { base materials } \\
\text { Standoff distance: } 15 \mathrm{~mm} \text { - Cavitation } \\
\text { samples: } 25.4 \mathrm{~mm} \times 25.4 \mathrm{~mm} \times 19 \mathrm{~mm} \\
\text { - Tap water } 22^{0} \mathrm{C}-\text { Upstream pressure } \\
23.8 \mathrm{MPa}-\text { Downstream pressure } 0.21 \\
\mathrm{MPa} \text { - Cavitation number of } 0.013- \\
\text { Velocity of } 218 \mathrm{~m} / \mathrm{s} \text {. }\end{array}$ & $\begin{array}{l}\text { A516 } \\
\text { S550QL } \\
\text { S690QL } \\
\text { S41500 }\end{array}$ & $\begin{array}{l}0.451 \\
0.494 \\
0.408 \\
0.406\end{array}$ & $\begin{array}{l}0.882 \\
0.921 \\
0.968 \\
0.868\end{array}$ & $\begin{array}{l}0.5065 \\
0.5080 \\
0.5070 \\
0.5076\end{array}$ & $\begin{array}{l}0.905 \\
0.920 \\
0.93 \\
0.98\end{array}$ \\
\hline $\begin{array}{l}\text { [7] Cavitation liquid jet erosion tests - } \\
\text { Welding overlay materials } \\
\text { Standoff distance: } 15 \mathrm{~mm} \text { - Cavitation } \\
\text { samples: } 25.4 \mathrm{~mm} \times 25.4 \mathrm{~mm} \times 19 \mathrm{~mm} \\
\text { - Tap water } 22^{0} \mathrm{C}-\text { Upstream pressure } \\
23.8 \mathrm{MPa} \text { - Downstream pressure } 0.21 \\
\mathrm{MPa} \text { - Cavitation number of } 0.013- \\
\text { Velocity of } 218 \mathrm{~m} / \mathrm{s} \text {. }\end{array}$ & $\begin{array}{l}\text { A516 } \\
\text { DS } 110 \\
\text { EC308LSI }\end{array}$ & $\begin{array}{l}0.382 \\
0.363 \\
0.465\end{array}$ & $\begin{array}{l}0.965 \\
0.933 \\
0.982\end{array}$ & $\begin{array}{l}0.667 \\
0.582 \\
0.341\end{array}$ & $\begin{array}{l}0.982 \\
0.981 \\
0.986\end{array}$ \\
\hline [8] Vibratory device. & $\begin{array}{l}\text { STEEL1040 } \\
\text { Hardened with laser } \\
\text { Non quenced } \\
\text { quenced }\end{array}$ & $\begin{array}{l}0.571 \\
0.671\end{array}$ & $\begin{array}{l}0.906 \\
0.936\end{array}$ & ---- & ---- \\
\hline $\begin{array}{l}\text { [8] Vibratory device -Thermal } \\
\text { treatment - }\end{array}$ & $\begin{array}{l}\text { CU- } 10 \% \text { AL } \\
\text { Cooling in oil } \\
\text { Cooling in air } \\
\text { Cooling in water } \\
\text { Cooling in water }\end{array}$ & $\begin{array}{l}0.1677 \\
0.195 \\
0.32 \\
0.415\end{array}$ & $\begin{array}{l}0.889 \\
0.856 \\
0.862 \\
0.912\end{array}$ & $\begin{array}{l}1.077 \\
0.585 \\
0.55 \\
0.543\end{array}$ & $\begin{array}{l}0.898 \\
0.909 \\
0.935 \\
0.915\end{array}$ \\
\hline [9] Vibratory device & $\begin{array}{l}\text { OL370-3K } \\
\text { 40Cr10 } \\
\text { STEEL IIIRNR } \\
\text { OLC45 }\end{array}$ & $\begin{array}{l}0.65 \\
0.551 \\
0.523 \\
0.511\end{array}$ & $\begin{array}{l}0.968 \\
0.977 \\
0.956 \\
0.968\end{array}$ & $\begin{array}{l}---- \\
---- \\
---- \\
----\end{array}$ & $\begin{array}{l}--- \\
---- \\
---- \\
----\end{array}$ \\
\hline
\end{tabular}


Table (1): Cont.

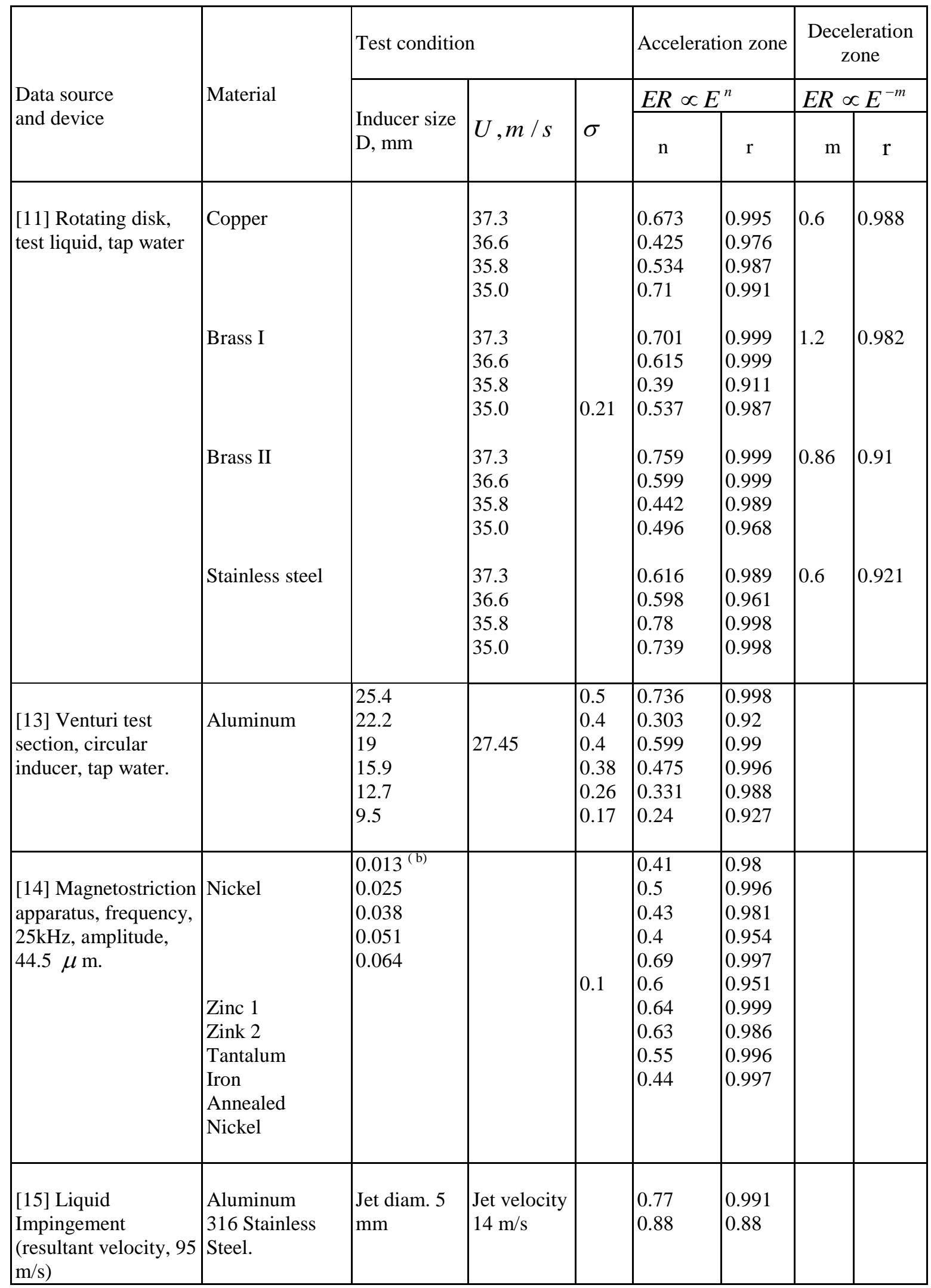




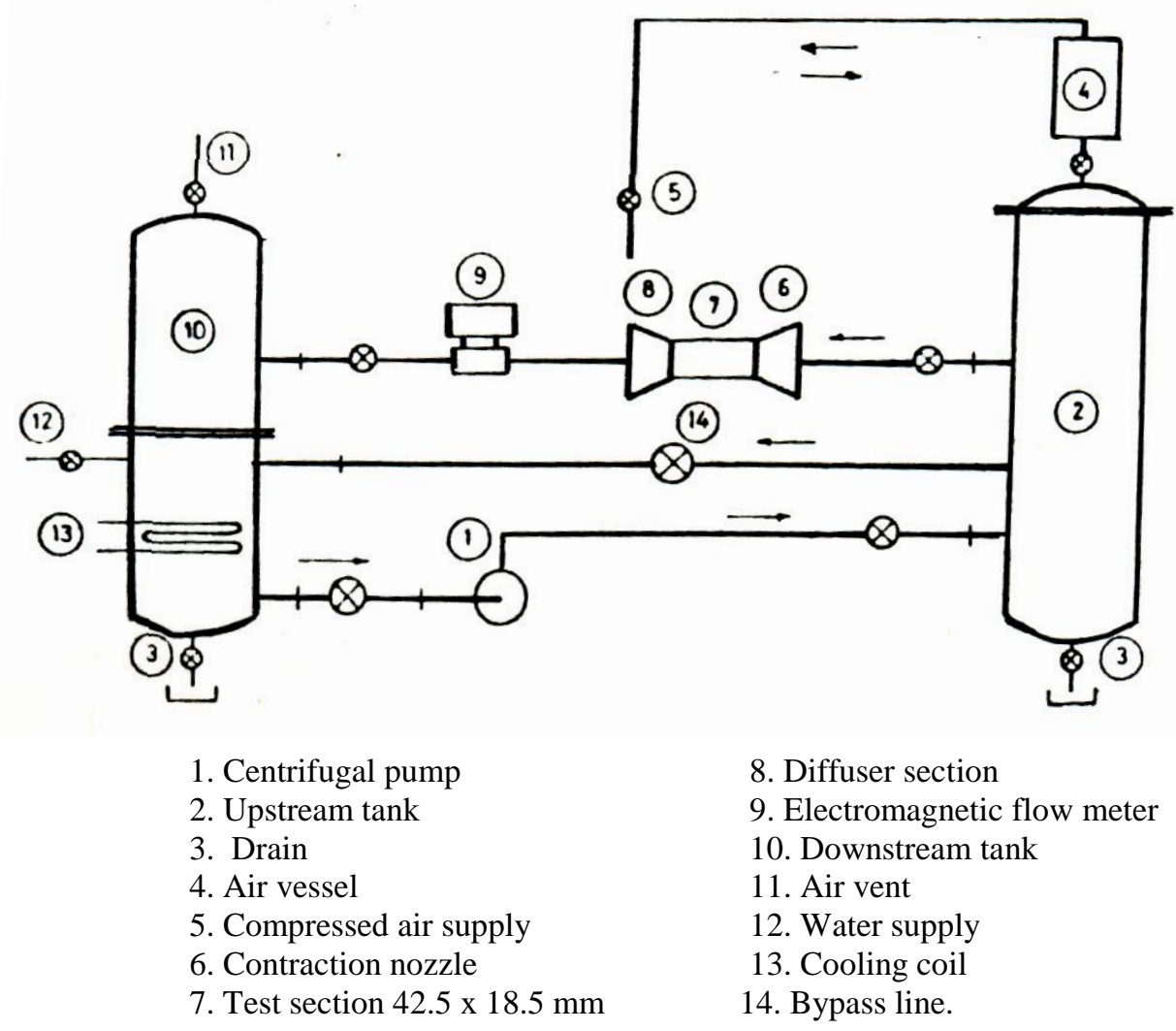

Fig.1 Cavitation research water tunnel and a list of its major components.

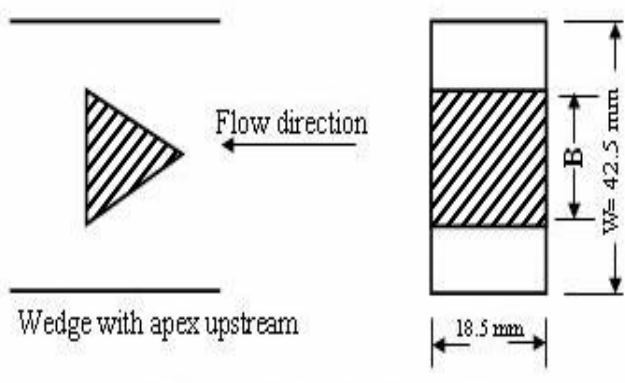

Position of the wedge in the test section
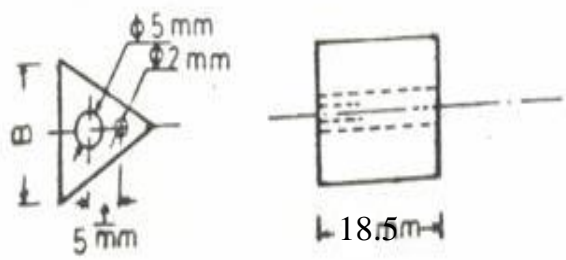

$\llcorner 18.5 m-d$

Fig. 2 Details of 600 symmetrical wedge and its position in the test section.

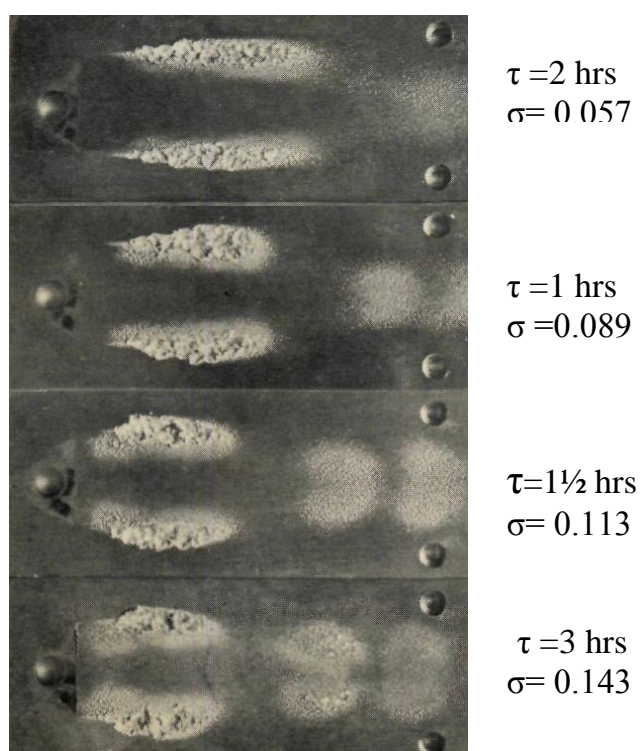

Fig.3 Photographs of the erosion patterns produced by $22 \mathrm{~mm}$ equilateral triangular $\left(60^{\circ}\right.$ symmetric wedge) for sidewall aluminum specimens at a constant flow velocity of $37.39 \mathrm{~m} / \mathrm{s}$, with different cavitation numbers. 


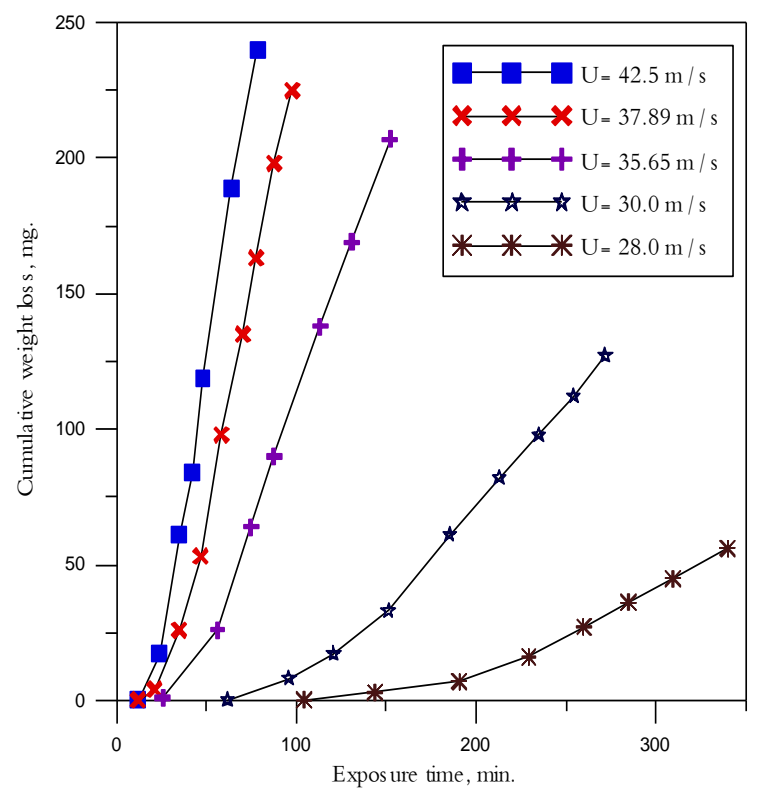

Fig.4 Weight loss (WL) as a function of time $(\tau)$ at various throat velocities with constant $\sigma$ of 0.113 using $15 \mathrm{~mm}$ 60o symmetrical wedge source.

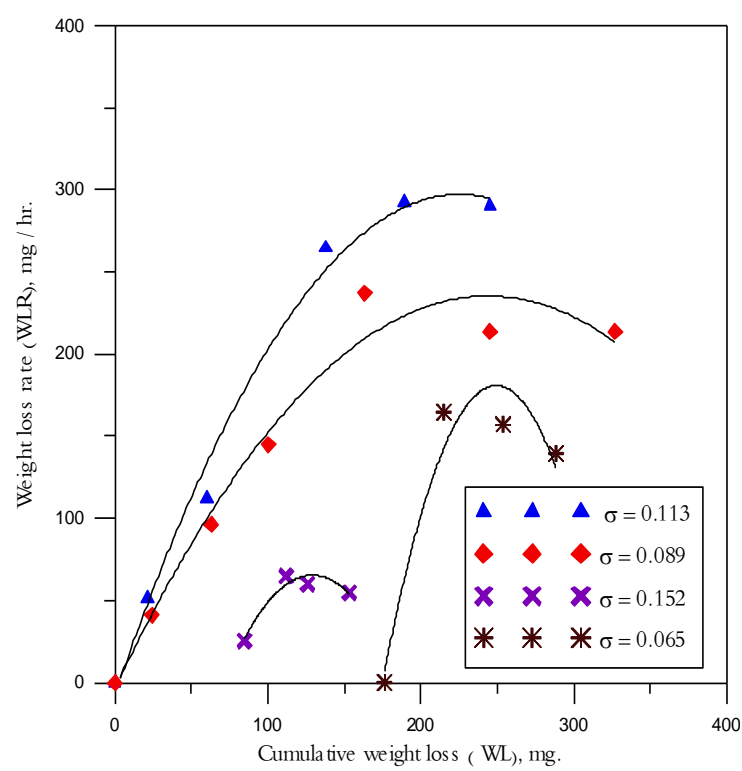

Fig.6 Typical weight loss rate (WLR) versus weight loss (WL) curves at constant throat velocity of 37.89 $\mathrm{m} / \mathrm{s}$ for various cavitation numbers $(\sigma)$ using 17 $\mathrm{mm} 60$ o symmetrical wedge source.

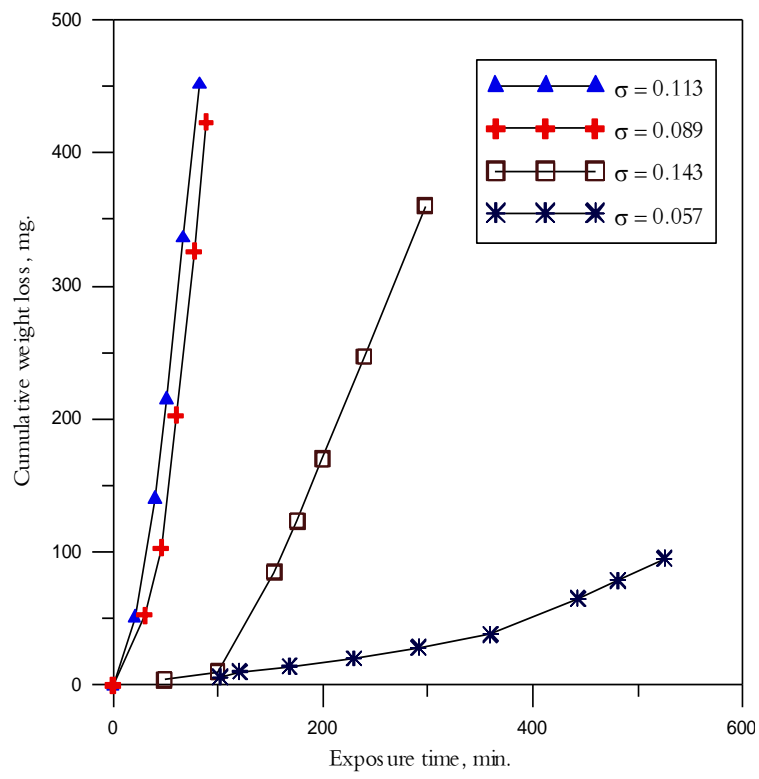

Fig.5 Weight loss (WL) as a function of time ( $\tau$ ) at various cavitation numbers with constant throat velocity of $37.89 \mathrm{~m} / \mathrm{s}$ using $22 \mathrm{~mm} \mathrm{60o} \mathrm{symmetrical}$ wedge source.

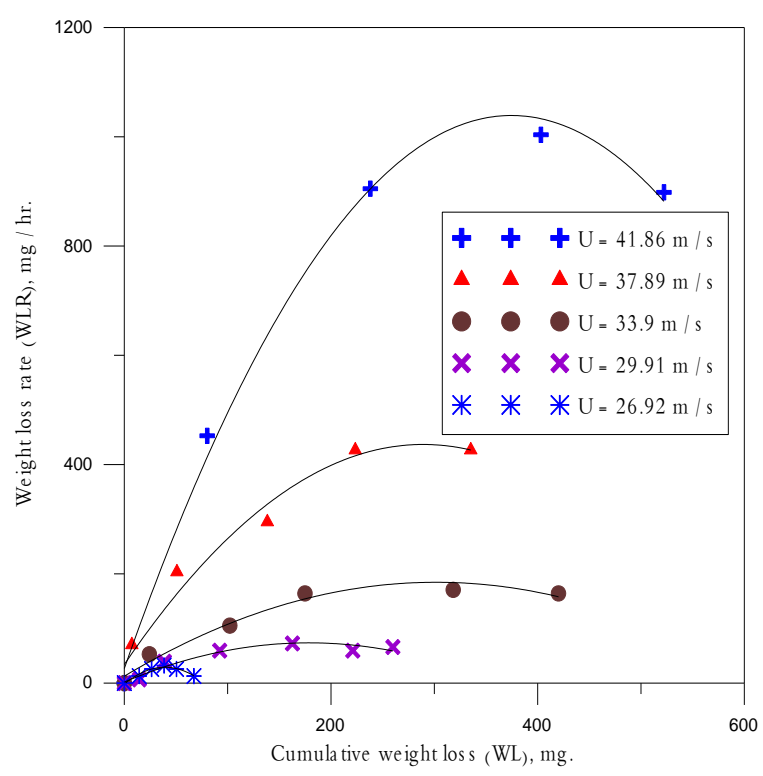

Fig.7 Typical weight loss rate (WLR) versus weight loss (WL) curves at constant $\sigma$ of 0.113 for various throat velocities using $22 \mathrm{~mm} 60 \mathrm{o}$ symmetrical wedge source. 
M. A. Hosien and S. M. Selim, "Predection of Cavitation Erosion Rate"

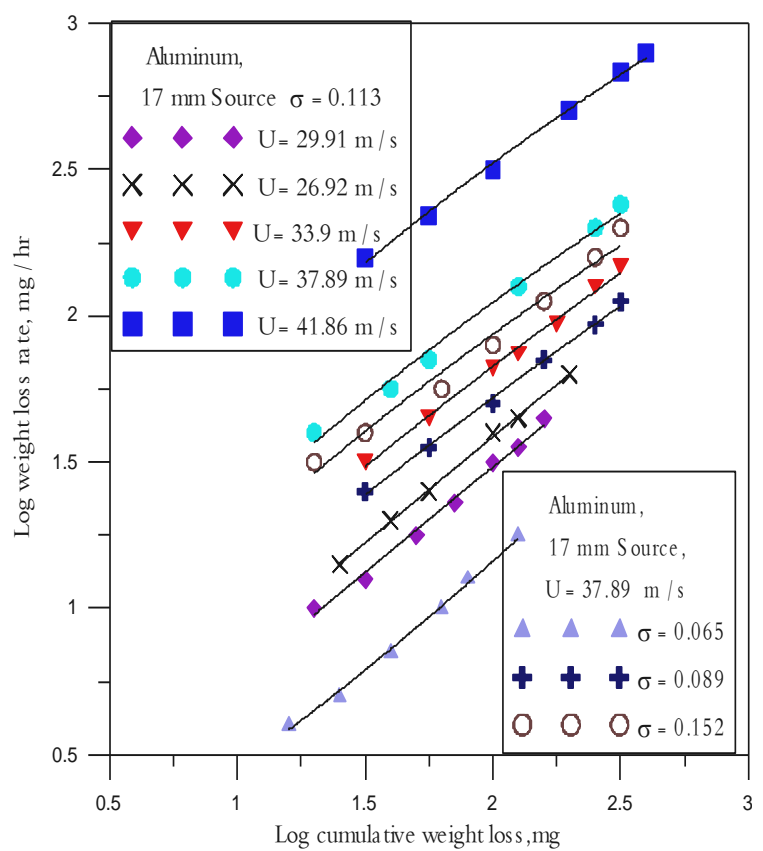

Fig. 8 Typical erosion rate versus cumulative weight loss

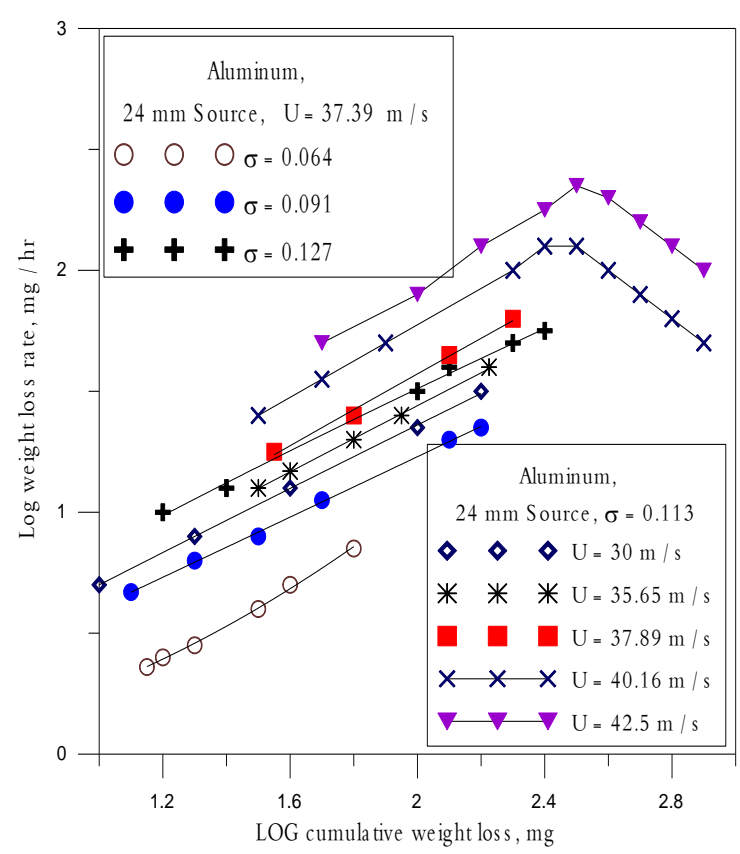

Fig.10 Weight loss rate versus cumulative weight loss.

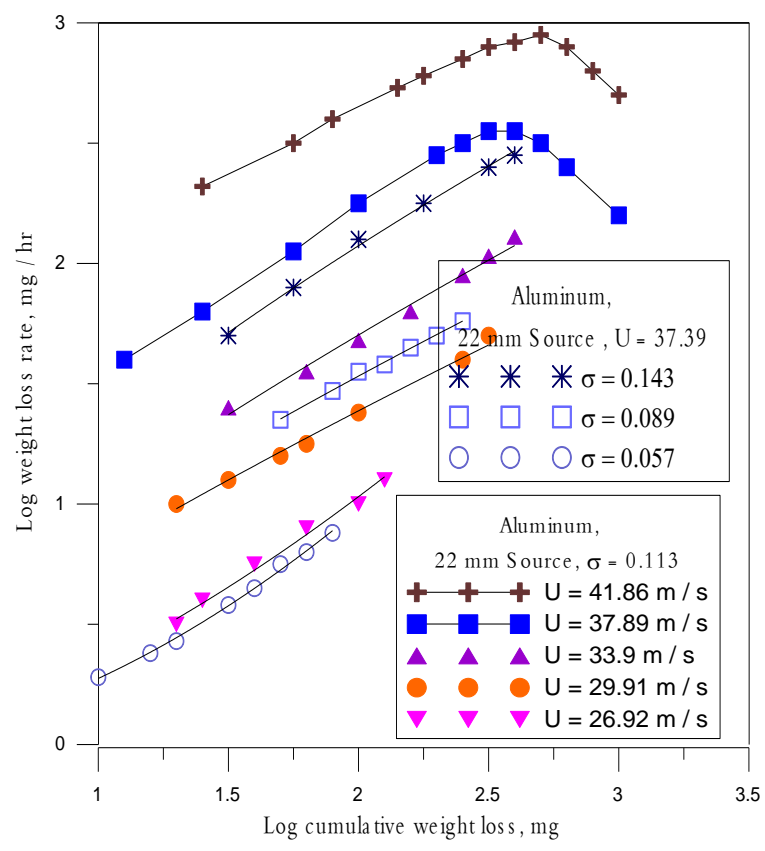

Fig. 9 Typical weight loss rate versus cumulative weight loss

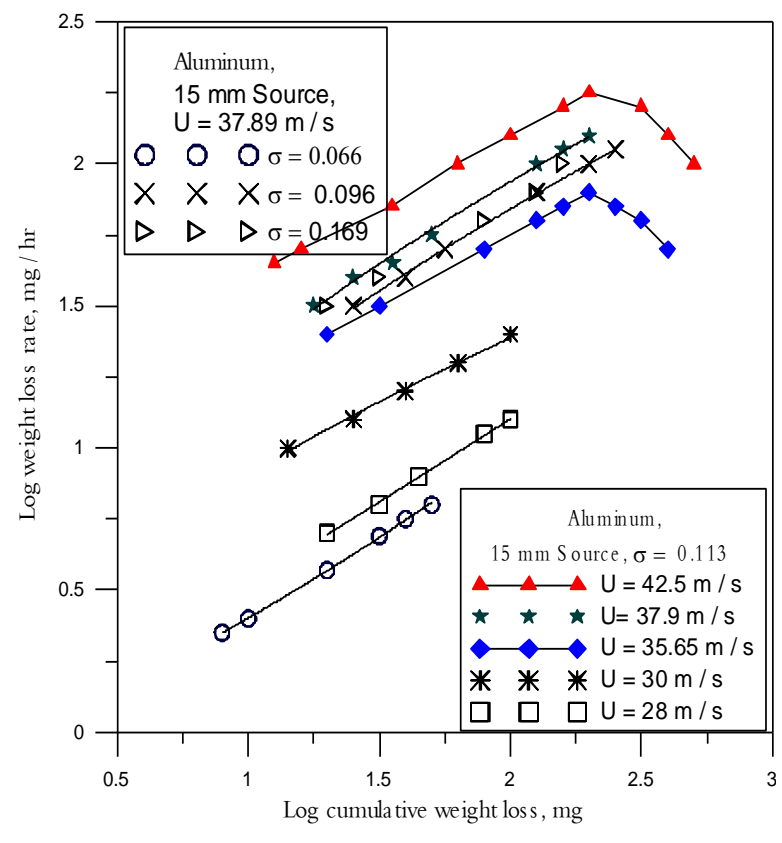

Fig. 11 Cumulative weight loss versus weight loss rate 


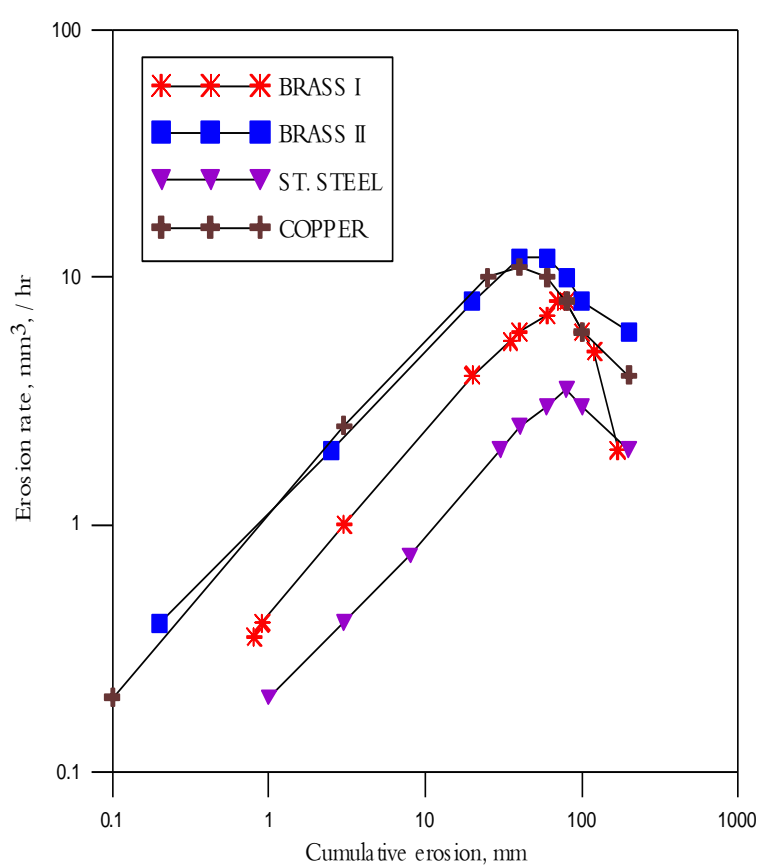

Fig. 12 Typical erosion rate versus cumulative erosion in a rotating disk device, (Data source: [11])

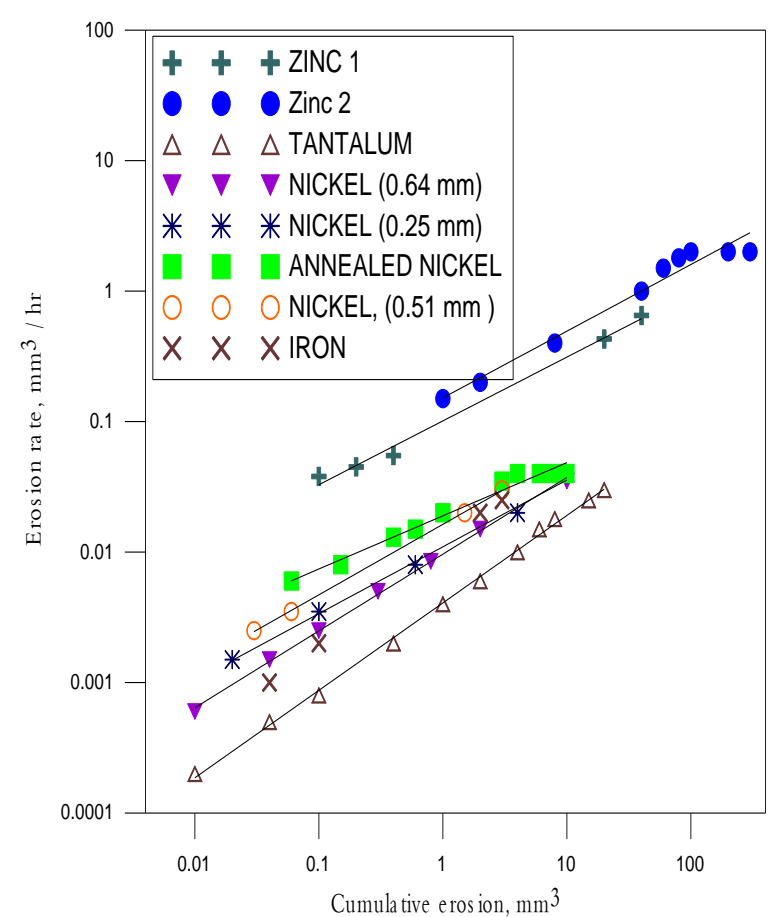

Fig. 14 Typical erosion rate versus cumulative erosion in a magnetostriction device, (Data source: [14]).

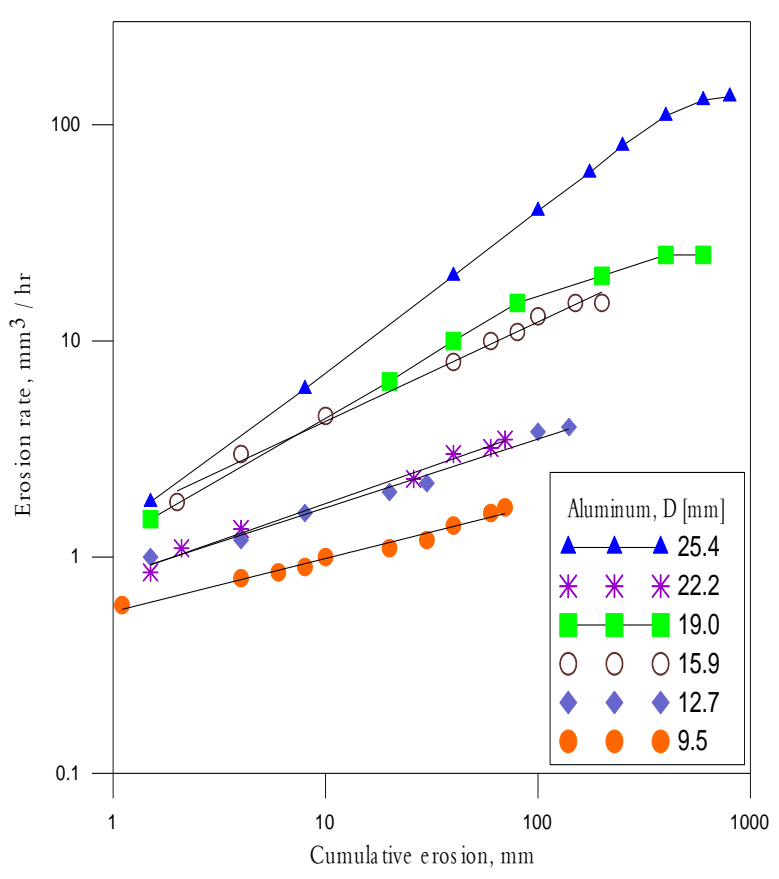

Fig. 13 Typical erosion rate versus cumulative erosion in a venturi device,

(Data source: [13])

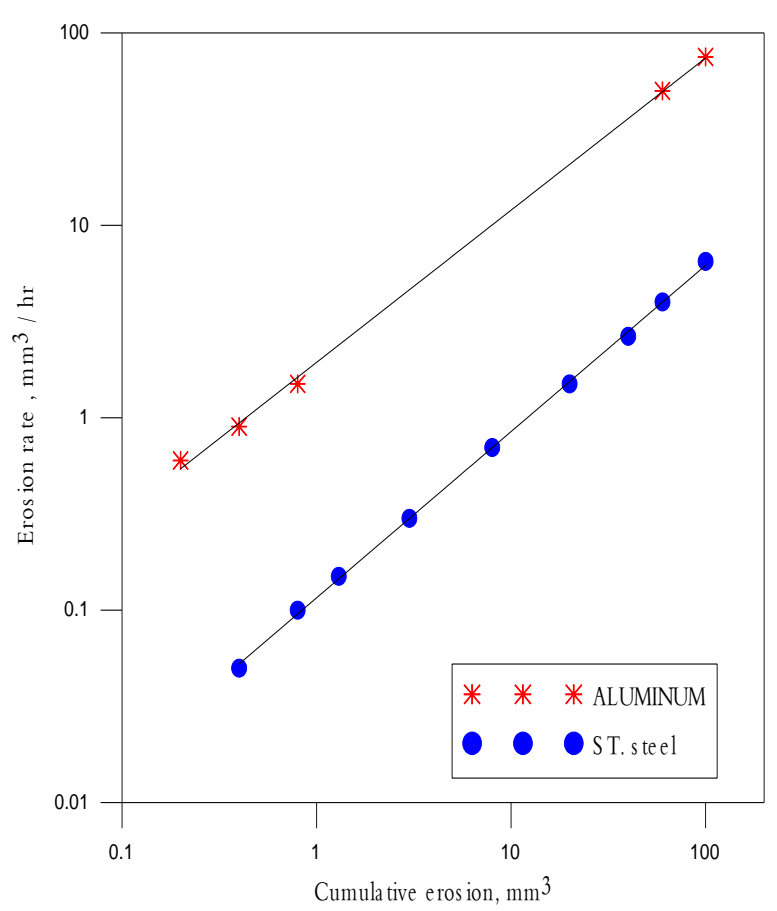

Fig. 15 Typical erosion rate versus cumulative erosion in a liquid impingement device,

(Data source: [15]). 
M. A. Hosien and S. M. Selim, "Predection of Cavitation Erosion Rate"

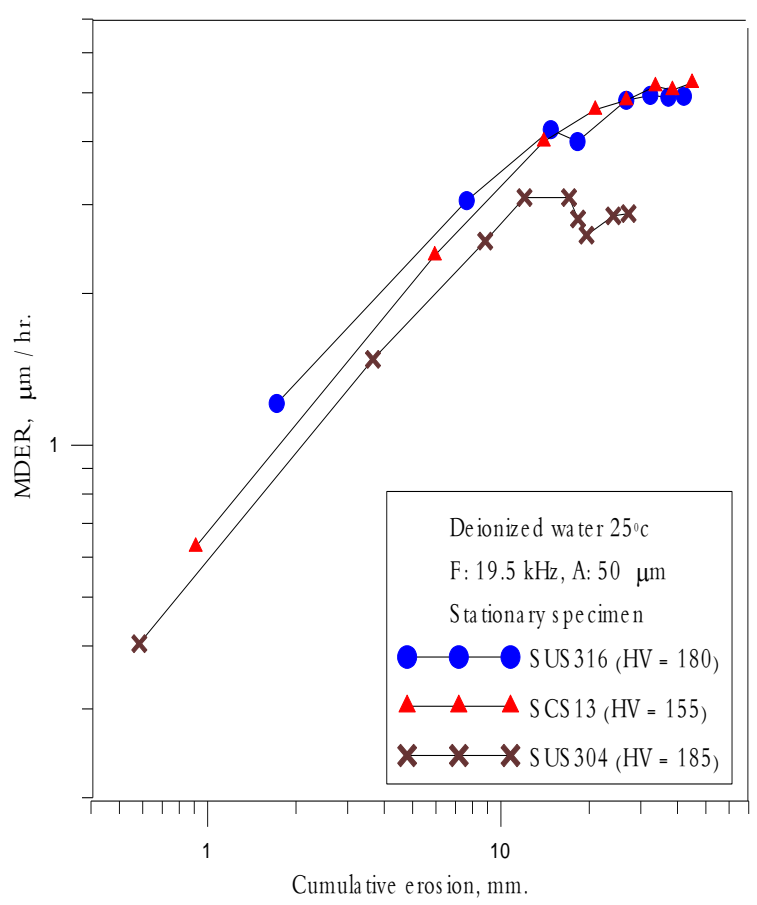

Fig. 16 Typical erosion rate versus cumulative erosion, (Data source: [4])

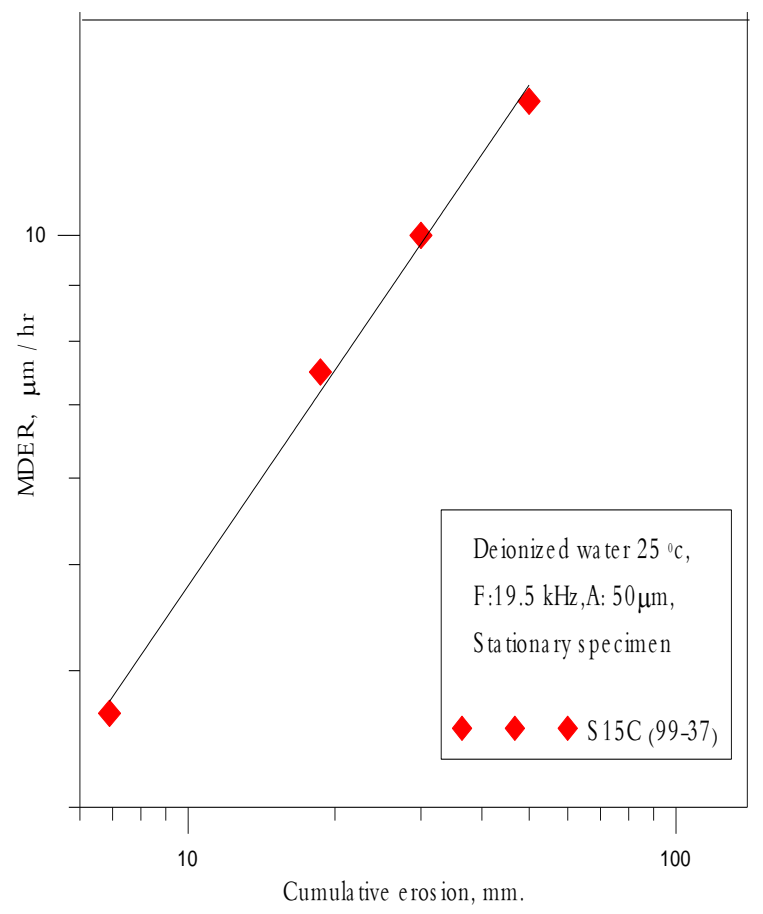

Fig. 18 Typical erosion rate versus cumulative erosion (Data source: [5])

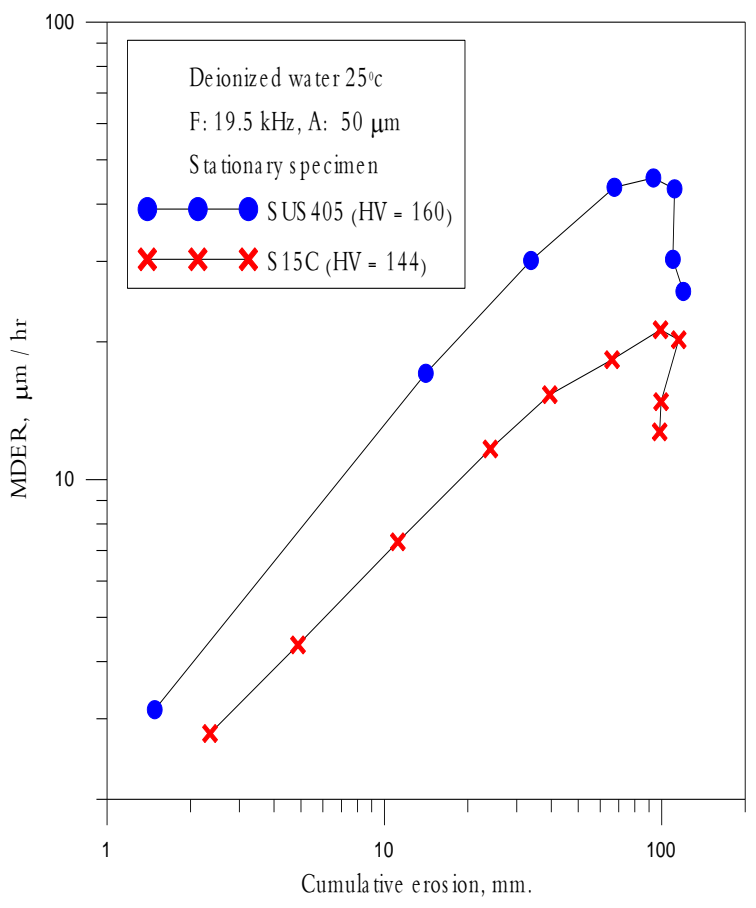

Fig. 17 Typical erosion rate versus cumulative erosion, (Data source: [4])

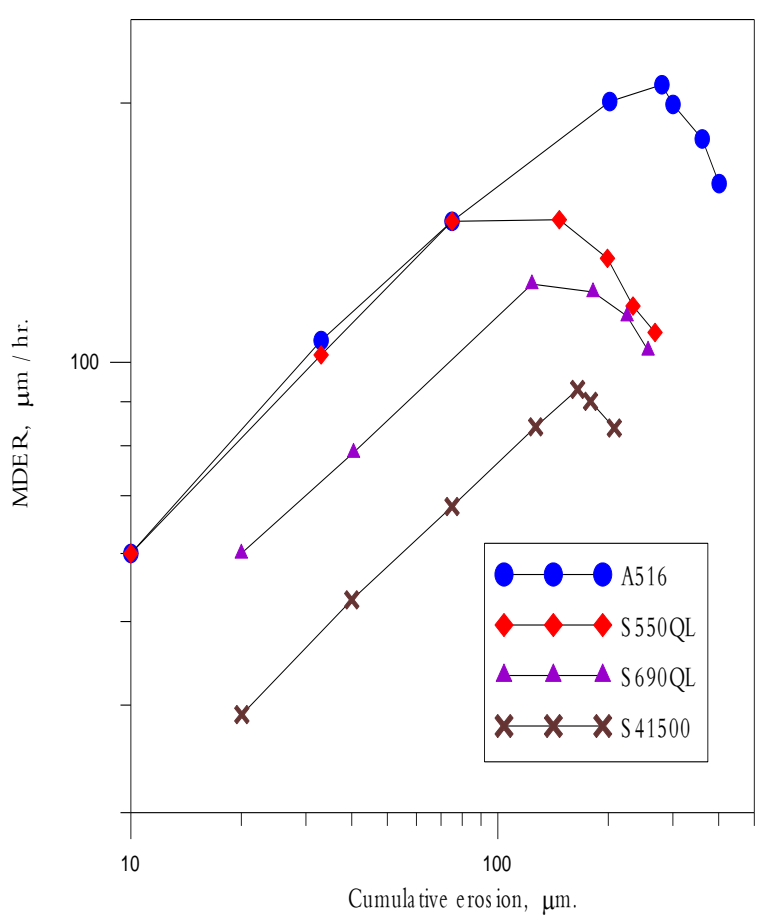

Fig. 19 Typical erosion rate versus cumulative erosion, (Data source: [7]) 


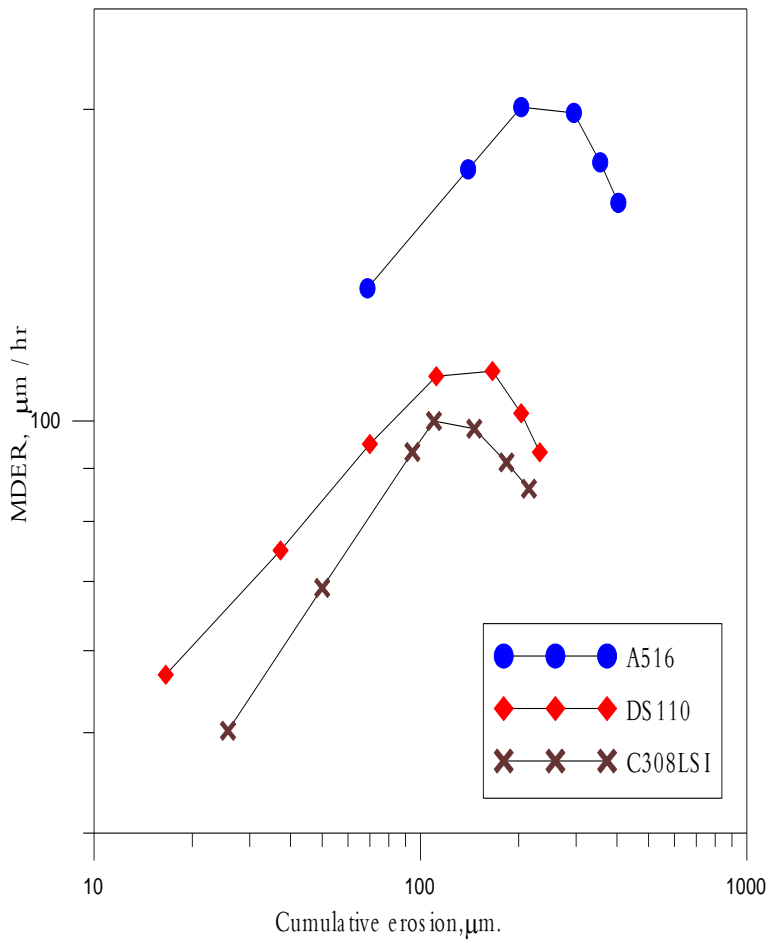

Fig. 20 Typical erosion rate versus cumulative erosion, (Data source: [7])

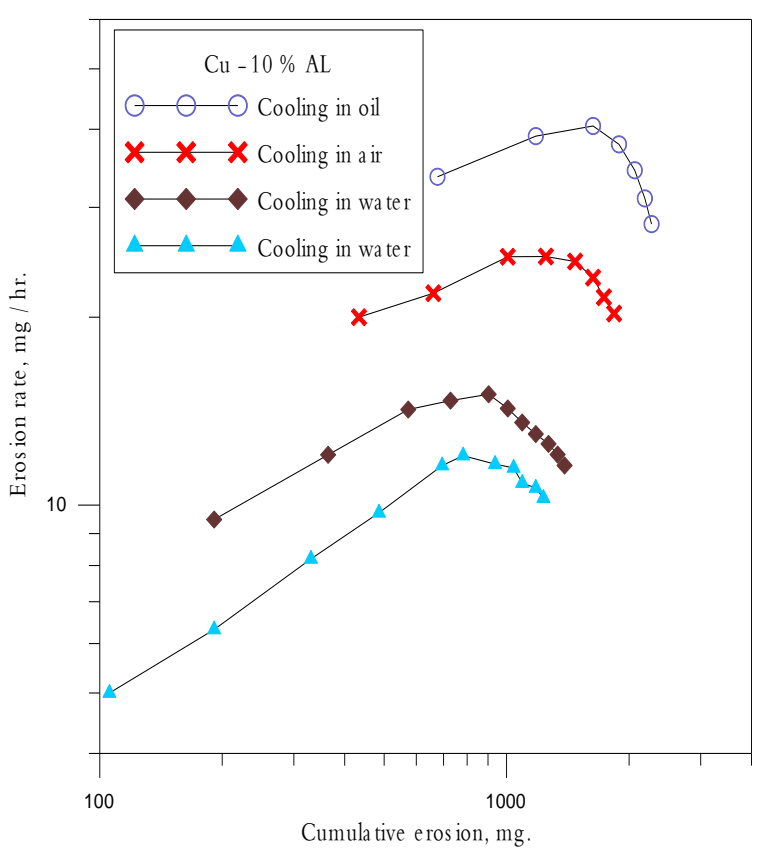

Fig. 22 Typical erosion rate versus cumulative erosion, (Data source: [8])

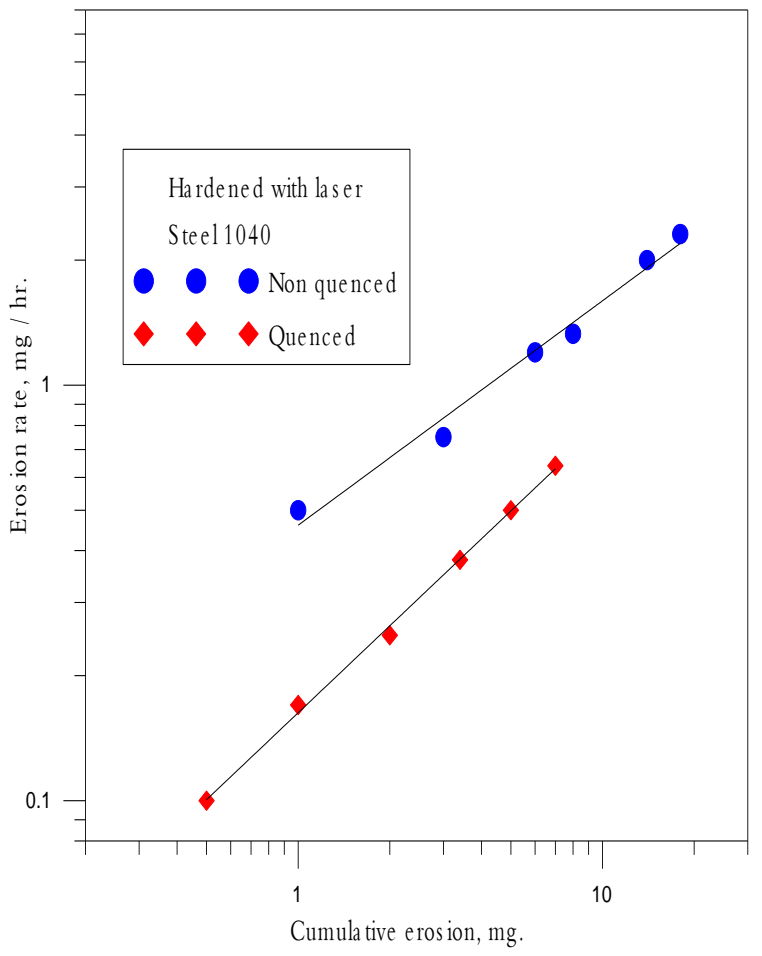

Fig. 21 Typical erosion rate versus cumulative erosion, (Data source: [8])

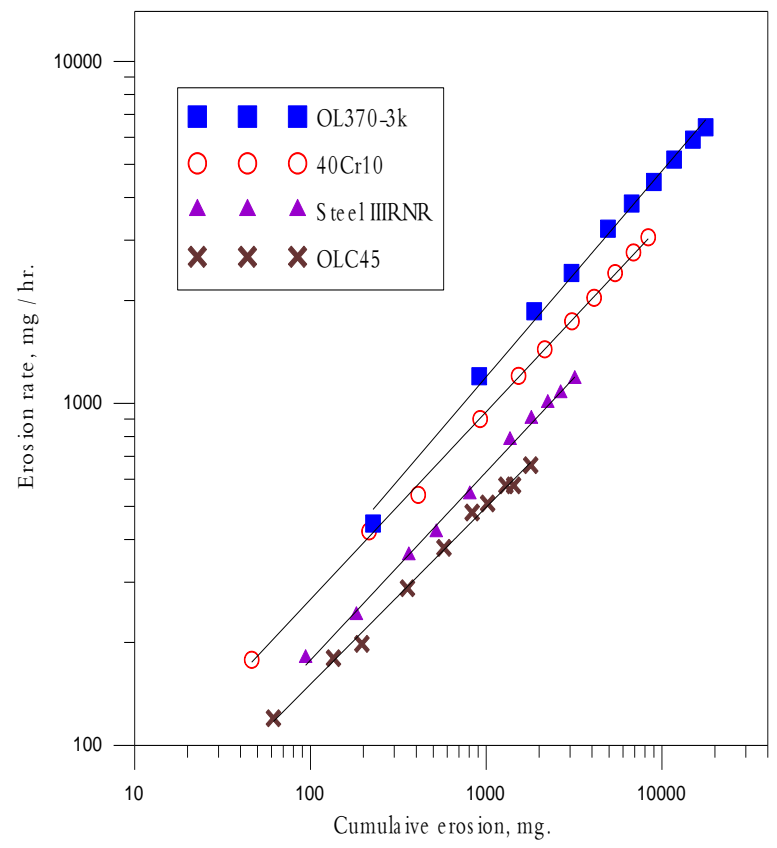

Fig. 23 Typical erosion rate versus cumulative erosion, (Data source: [9]) 